\title{
The Use Of Statistical Sampling And A Single-Point Estimator To Establish Punitive Fines In Compliance Auditing: A Cautionary Note
}

Steven W. Lamb, Indiana State University, USA William H. Svihla, Indiana State University, USA Jeffrey S. Harper, Indiana State University, USA

\begin{abstract}
This paper describes current practices relating to statistical sampling used by auditors performing compliance audits. An example audit case is presented where a compliance audit is performed using statistical sampling. Fines for non-compliance are based upon the sample results. While the practice is quite common and generally accepted, there are significant ramifications associated with the use of a single-point estimator. Approximately half of the time, an auditee will be charged more than is actually deserved. We explore the shortcomings associated with the use of a single-point estimator and the appropriateness of the use of a one-tailed confidence interval to provide greater assurance that fines are appropriate and reasonable.
\end{abstract}

Keywords: audit sampling, sampling risk, confidence intervals, compliance audit, projected values.

\section{INTRODUCTION}

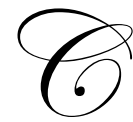

ompliance audits have become a prevalent form of process assessment in an array of businesses and industries today. While the financial auditor is charged with rendering an opinion on whether a client's financial statements are fairly stated, the compliance auditor's duty is to determine whether an organization has complied with applicable laws, regulations, contractual agreements, or other specific rules and standards. Often, the collection and use of public funds is the focus of compliance audits. Additionally, many organizations in the private sector that are subject to government regulation are required to receive independent compliance audits, either through CPAs in public practice or by the regulatory authorities themselves.

The results of these audits often have significant consequences. Frequently, the findings of a compliance audit are used as a basis for monetary settlement, or even testimony in civil and criminal trials. As such, the findings are of great importance to both the auditee and the constituency represented by the auditor.

Because of the nature of compliance audits, the auditor is often called upon to determine whether a large volume of transactions has been properly processed. Sampling is a common and accepted practice when it is not practical to review every transaction. In some cases, an examiner will use a sample of convenience as discussed later in this paper. The use of statistical sampling methods, however, is a more formal and defensible form of sampling that is often preferred or required as part of an engagement.

In this paper, we examine current compliance audit practices relating to the statistical sampling of large populations of transactions and subsequent projection of the findings to the population as a basis for punitive fines. As we discuss the ramifications of these practices, we use the example of a compliance audit of an ambulance company whose charges are regulated and is subject to fines for incorrect charges, Specifically, the auditor uses 
statistical sampling to determine a single-point estimator of overcharges. The estimator is then projected to the entire population of customer charges during the audit period to determine a punitive fine amount for audit settlement. Finally, we draw conclusions and implications concerning the use of this approach, and suggest an alternative methodology using basic sampling theory.

\section{GUIDANCE FOR STATISTICAL AND NON-STATISTICAL SAMPLING}

The problems associated with audit sampling (both the statistical and non-statistical approaches) have been discussed at various times in the past (Teitlebaum and Robinson, 1975; Epstein, 1986; Smieliauskas, 1986; Fowler and Foster, 1994; Hitzig, 1995 and 2004; Messier, Kachelmeier, and Jensen, 2001; Gilbertson and Herron, 2003; MTC, 2007; among others). The presence of substantial guidance provided to practitioners by professional organizations indicates that there must have been some level of misunderstanding when applying sampling techniques in practice. With the apparent goal of clarifying guidelines and thus practices, both the Auditing Standards Board (ASB) of the American Institute of Certified Public Accountants (AICPA) have issued standards governing the use of audit sampling in engagements The AICPA has codified in section AU 350 of its Authoritative Standards and Related Guidance for Nonissuers: Statements on Auditing Standards, its previous Statements of Auditing Standards (SAS) 39, 43, 45, and 111. AU 350 provides guidance to practitioners for the applications, use and interpretation of statistical and non-statistical sampling techniques in financial statement audits. ${ }^{1}$ Also, the AICPA has published materials and presented continuing education courses on sampling techniques in financial statement audits. Its reference, Audit Sampling, is a standard in the profession that has been integrated into many auditing textbooks and serves as the basis for sampling guidance in PPCs audit planning resources (AICPA, 2008).

The AICPA's auditing standards ${ }^{2}$ permit both statistical and non-statistical sampling techniques. Statistically-based substantive and test of control procedures, by design, control for sampling risk in the design of sample sizes, the selection of the sample, and the evaluation of the results for a given confidence level. ${ }^{3}$ In use, a sample's estimate of an account balance or a monetary misstatement is projected to the population. A confidence interval is then computed for the account balance or class of transactions. In evaluating the sample results, the client's account balance is compared to the auditor's confidence interval to determine if it falls within the confidence interval. If it does, the client's account balance is presumed to be fairly stated; if the client's account balance does not fall within the auditor's confidence interval, the client's balance is likely to be materially misstated. The client must then search for and correct the monetary misstatement in the account balance (class of transactions), when added to other uncorrected errors in the financial statements, or be willing to accept a qualified or adverse audit opinion on the financial statements. ${ }^{4}$

\section{Non-Statistical Sampling}

Where non-statistical approaches are used in a financial statement audit, an effort is still made to control for sampling risk. When non-statistical sampling is used, the AICPA requires that the sample size selected from the population must approximate the sample size determined using a statistical approach (SAS 111, AU 350). While a

\footnotetext{
${ }^{1}$ Standards for public company financial statement auditors are established by the Public Company Oversight Board (PCAOB). However, the PCAOB standards reference the AICPA's SAS as interim standards, of which there have been no modifications to the area of audit sampling.

${ }^{2}$ These standards include Statements on Auditing Standards (SAS) 39 (June 1981), 43 (August 1982, superseded, 45 (August 1983), and 111 (February 2006).

${ }^{3}$ In substantive audit testing, these risks are referred to as the risk of incorrect acceptance and the risk of incorrect rejection. The risk of incorrect acceptance refers to accepting a client's balance as fairly stated when, in fact, it is not. The risk of incorrect rejection refers to rejecting a client's account balance as fairly stated when, in fact, it is stated fairly. The first risk relates to the effectiveness of the audit; the second, the efficiency of the audit (AICPA, Audit Sampling, AU 350.12). Guidance for setting these risks is contained in AU 312 Audit Risk and Materiality in Conducting an Audit (AICPA, AU 312.26).

${ }^{4}$ Under an alternative approach, the auditor's estimate of the monetary misstatement in the account balance or class of transactions is then adjusted for sampling risk to arrive at an upper (lower) estimate of the monetary misstatement in the account or class of transactions. This is then compared to the auditor's tolerable error for the account to determine if there is a likely material misstatement in the account balance or class of transactions.
} 
confidence interval is not, nor can be, computed in non-statistical sampling, the approach recommended by the AICPA tacitly controls (to some degree) for sampling risk by ensuring the sample size is sufficiently large to permit the projection of the results to the population. This provides the auditor with some assurance that the results do not have an unduly large sampling error due to a small sample size.

When using non-statistical sampling an auditor compares the projected estimate of the misstatement present in the account (class of transactions) to the tolerable error. The auditor then makes a mental determination as to whether the projected value is too close to the limits established by the tolerable error for the auditor to be comfortable that the account balance is not materially misstated. However, this process provides no statistical assurance that the auditor's projection of error is reasonable. This estimate may still suffice for purposes of the audit as long as the projected error is not too close to the tolerable misstatement. This problem underscores the need for auditor judgment in evaluating the evidence obtained during the audit. Where the only source of audit evidence about the assertion is the non-statistically derived sample results, an auditor would normally be very wary of projected values that are close to the limits established by tolerable error. In such cases, the auditor may increase the sample size, obtain other types of evidence, or conclude there is a good likelihood that the account balance is materially misstated.

The Institute for Internal Auditors (IIA) provides its members with guidance in using statistical and nonstatistical sampling in the form of a practice advisory. While terminology is similar to that of the AICPA, the IIA restricts the use of non-statistical sampling to only making determinations about the sample. It specifically prohibits extrapolating the results of a nonstatistical sample to the population because the nonstatistical sample results are "unlikely to be representative of the population."

\section{Statistical Sampling}

Hall, Hunton, and Pierce (2002) surveyed auditors in public accounting, industry, and in state and federal governmental agencies to determine sampling practices in use. In their study, they found that thirty-six percent of all practicing auditors used some form of formal statistical evaluation of sample results. All of the respondents reported relying on employer-provided standards when needing guidance, most reported relying also on AICPA audit standards, the AICPA's Audit Guide: Audit Sampling (for statistical tables), or software (e.g., Microsoft Excel's Analysis Toolpak) that is based on statistical formulas.

In a summary of The Wisconsin Study, an exhaustive survey of all forty-six states having a sales tax, Annulli et. al. (2000b), reports that twenty-five of the forty-six states (54\%) used some form of statistical sampling techniques during sales and use tax audits. Of these, twenty report computing a precision and/or a confidence interval of the audited sales tax assessment. The confidence interval percentages varied substantially across the twenty-five states reporting the use of confidence intervals. Confidence intervals ranging from $70 \%$ to $99 \%$ were reported. The majority (75\%) reported using two-tailed confidence intervals. The remainder reported either adjusting the estimate downward from the projected mean value based on negotiations with the taxpayers or using the lower bound of the estimate to assess the tax liability. The implications of adjusting the estimate or using the lower bound will be discussed later in this paper.

Gavenda (2001) reported in her study that twenty-two (of forty-six) states used some form of statistical sampling in sales and use tax audits. Of these states, $72 \%$ projected assessments using either the mean value only or using the upper limit of a computed confidence interval. Only four states based added sales and use tax assessments on the lower bound of their confidence interval. Thus, a majority of states either assessed additional tax liabilities based on the mean value (the sample results) or on the upper bound of a 90-95\% confidence interval. The four states basing the additional tax liability on the lower bound of the confidence interval were in essence absorbing much of the sampling risk that the other forty-two states were unwilling to accept. Additionally, the Gavenda noted that credits and adjustments were frequently ignored when evaluating the sample results for purposes of assessing

${ }^{5}$ Practice Advisory 2100-10: Audit Sampling (PA 2010-10) 
additional tax liabilities. Thus, the joint effects of failing to consider sampling risk and ignoring credits and adjustments in assessing additional tax liability, increases the potential for taxpayers to pay more than what is "fair."

Medicare provides for comprehensive post-payment medical reviews (MR) of providers suspected in providing non-covered or medically unnecessary services. These compliance audits focus on determining whether providers' medical services are reasonable and necessary under Medicare law; whether they adhere to providers' orders and plans for treatment; whether they adhere to coverage requirements; and, whether provider documentation is present to support the assertion that the services were furnished.

MRs are performed by intermediaries through on-site reviews when claims volume is high and reflects a pattern of erroneous billing or over-utilization, or when a case by case review is not administratively feasible. In performing a MR, an auditor may use statistical sampling to calculate and project the amount of any claim overpayment(s) or underpayment(s). While it can be used in assessing overpayments, the Medicare Prescription Drug, Improvement, and Modernization Act of 2003 (MPIMA) restricts the use of statistical sampling for assessing overpayments to those situations where "a sustained high level of payment error" exists, where educational efforts have failed to correct persistent billing irregularities or errors, or the provider fails to respond to a consent settlement agreement offer (Medicare Program Integrity Manual, Chapter 3, pp.65, 80-81).

In those cases where statistical sampling methodologies must be used, $90 \%$ confidence intervals are computed and applied to the sample results. The lower bound of the resulting confidence interval is then used for assessing the overpayment amount. If the lower bound is zero or negative, no overpayment is assessed. In most situations the lower limit of a one-sided 90 percent confidence interval will be used as the amount of overpayment to be demanded for recovery from the provider or supplier. This yields an estimate of the overpayment that is very likely less than the true amount of overpayment. Using the lower bound then allows for a reasonable recovery without requiring the tight precision in the estimate that might be needed to support a demand for the point estimate (mean value).

\section{Legal Implications Of Chosen Sampling Technique}

The sampling technique that is chosen to estimate overpayments or losses has important implications in cases that are involved in litigation. As part of their 2003 study of the effect of sampling methods on juror negligence awards, Glibertson and Herron cite the work of previous research into the use of both statistical and non statistical methods of sampling in cases involving negligence in the external auditor's performance on financial statement audits. These studies they suggest that, while statistical sampling methods may be preferable, jurors may have difficulty in understanding, or accepting, evidence based on a statistical sample, citing juror concerns as to whether statistical sampling is reliable. In the study, the probability of a guilty verdict was not significantly affected by the choice of sampling method. However, cases involving statistical sampling had an average of forty-three percent lower damage awards than those with non-statistical sampling techniques. ${ }^{6}$

The issue as to whether statistical evidence will be accepted by the courts as a means of estimating losses or damages may be a significant factor in determining whether they will be used. The acceptability of statistical evidence for this purpose is determined, not by statistical experts, but often by the judge presiding over the case. Fowler and Foster (1994) describe the factors that make it more likely that a given court will accept sampling results as evidence when determining the amount of a loss or damage. ${ }^{7}$ They note that acceptability of statistics as evidence often hinges on whether the chosen sampling approach is clearly preferable, and yet still fair, for purposes of computing the overpayment or loss to that obtained by taking a census of the population. Typically, there should be

\footnotetext{
${ }^{6}$ Gilbertson and Herron's study was an empirical investigation involving a single mock court case tried before a jury pulled from an actual juror panel and from a student jury panel composed of junior business students. Their primary focus was on the sample size determined using statistical versus nonstatistical methods. There was no significant difference between the decisions made by the actual juror panel and the student juror panel.

7 This discussion focuses on the situations where there is no statutory guidance on the use, or the prohibition of the use, of statistical sampling.
} 
substantial evidence suggesting that taking a census would be more than a minor inconvenience. Second, the practice of using sampling to estimate losses or damages must clearly be generally accepted in the legal and regulatory environments. In cases involving health care payments, the courts have generally been willing to accept projections of sample estimates of overpayments. Third, credible experts must be available to justify the usefulness, reliability, and equity of the chosen method. The selection of the expert has perhaps the greatest effect on whether the projected loss or damage using statistical methods will be accepted by the court. As a cautionary note, Fowler and Foster note that courts will typically reject using sampling to project losses or damages when the method chosen is not generally accepted in practice or in the regulatory environment, when it is perceived to be inherently unfair or biased toward one party, or when the expert is not able to coherently explain the technical aspects of the procedure or how the technique was applied. ${ }^{8}$

\section{AN ILLUSTRATIVE CASE: A 2005 COMPLIANCE AUDIT}

In 2005, a local ambulance company received a routine compliance audit of the fees charged to its customers. The purpose of the audit was to determine whether the company had correctly charged the allowable amounts for services rendered. As a result of such audits, fines are typically levied against the companies that are found to have overcharged its customers. A statistical sample of customer invoices is often used to determine the fine amount.

An independent auditor took a sample of 146 customer invoices from the total population of 7,932 invoices. The auditor found sixty eight invoices that included overcharges not allowed in the ambulance company's contract. The total of the overcharges was $\$ 1,735.25$. Because of the nature of this compliance audit, undercharges were not recorded (they were less than the allowable maximum charge and, therefore, of no interest to the auditor). As such, the total amount overcharged was not offset with undercharges.

After additional documentation was provided by the ambulance company, the sixty eight claims found to contain overcharges within the sample were re-audited. As a result, the overpayment total of the sample was reduced to $\$ 1,145.00$, representing a mean overcharge of $\$ 7.842(\$ 1,145.00 / 146)$. This amount was used, in turn, to estimate the total of overcharges within the invoice population. The auditor used the average overcharge amount (\$7.842) found within the sample and projected it onto the invoice population to arrive at a value of $\$ 62,206.44$. This value represents the auditor's estimation of the total overcharges contained within the population of 7,932 invoices.

\section{The Shortcoming}

According to the central limit theorem, which is the foundation of much of inferential statistics, when sample sizes are sufficient, the sampling distribution of the mean can be approximated by the normal distribution. When single-point estimators (sample means) are repeatedly derived, there is an equal chance that the sample mean $(\bar{X})$ exceeds the true population mean ( $\mu$ or is less than the population mean. In other words, if the audit sampling procedure were to be used repeatedly on different ambulance companies, each potential audit would have a fifty percent probability of finding a value higher than the true amount of overcharges and a fifty percent probability of finding a value lower than the true amount.

The sampling approach will virtually never result in a "correct" value of the overpayments that are contained within the invoice population. As such and over time, the total of the under- and over-estimation inherent in this process will approach zero, which is much of the justification for the use of this process. However, fines are estimated one company at a time. It does an individual company no good to understand that in the long run, the average size of the fine is justified. An individual company wants assurance that its specific fine is justified. Our concern with the statistical sampling procedure used by the auditor in this example is that there is a significant potential for the company being audited to be substantially overcharged because of the nature of the process.

\footnotetext{
${ }^{8}$ Fowler and Foster make reference to the oft cited case Chaves County Home Health Care, Inc., et al. v. Sullivan, 931 F.2s 914 (D.C. Cir.), cert. denied 112 S.Ct. 1160 (1992) which provides considerable guidance on the application and acceptability of statistical evidence for estimating overpayments.
} 


\section{The Remedy}

The sample mean $(\$ 7.842)$ found in this process is only an estimate of the true average overcharge per invoice. The standard error associated with the estimate is about $\$ 1.50$ (\$1.496). In repeated sampling, there is approximately a 32 percent chance that the true population mean will be one standard error or more from its estimate (the sample mean). The chance that the true mean will be more than two standard errors away from the sample mean is only five percent (approximately). Therefore, if the auditor reduced the sample mean by two standard errors $(\$ 3.00$ in this case) prior to projecting it to the population, there would only a small probability ( 2.5 percent chance) of levying an excessive fine. The auditor would assign a $\$ 4.84$ value to be projected onto the population instead of the sample mean value of $\$ 7.84$. Reducing the estimate by two standard errors provides greater assurance that the estimated value of overcharges does not substantially exceed the true value of the overcharges. While this procedure would give greater assurance that an auditee would not be fined an amount greater than the true amount of overcharges, we can refine this process further so that the auditor is able to specify audit risk to a predetermined level of confidence, as shown below.

\section{Development Of A One-Tailed Confidence Interval To Avoid An Excessive Fine}

The object of the auditing procedure is to determine the total value of customer overcharges by the company. Using basic statistical theory associated with the distribution of sample means, a statistical process can be developed so that the probability of an excessive fine to an individual company is reasonably small. Use of a onetailed confidence interval for the population mean can ensure that the chance of an excessive fine is determined prior to sampling. The auditor will determine the level of confidence (ninety-nine percent, ninety-five percent, et cetera) that the fine will not be excessive. Again, the procedure actually used by the auditor in our example above guarantees that approximately half the companies audited will pay a larger fine than the true amount of overcharges. Some will pay substantially excessive fines.

Since the size of the fine is directly tied to the estimate of the population mean $(\bar{X})$, the probability statements that are developed must use $\bar{X}$. A probability statement can be developed to assure all parties that a company is unlikely to pay an excessive fine.

$\mathrm{P}\left(\bar{X}<\mu+t_{\alpha} \cdot s_{\bar{X}}\right)=1-\alpha$

Formula 1 is a result of the central limit theorem. Sample means are normally distributed. Manipulating this formula algebraically, the following is obtained:

$\mathrm{P}\left(\mu>\bar{X}-t_{\alpha} \cdot s \bar{X}\right)=1-\alpha$

Multiplying both sides of the inequality by the population size yields:

$\mathrm{P}\left[\mathrm{N} \mu>\mathrm{N}\left(\bar{X}-t_{\alpha} \cdot s_{\bar{X}}\right)\right]=1-\alpha$

Essentially, this formula makes certain that the amount charged to the auditee $\left(\mathrm{N}\left(\bar{X}-t_{\alpha} \cdot s_{\bar{X}}\right)\right)$ will be less than the true amount of overcharges $1-\alpha$ percent of the time. Conversely, this statement ensures that the auditee will be overcharged only $\alpha$ percent of the time. In this formula, $t_{\alpha}$ is determined with $n-1$ degrees of freedom using the specified value of alpha. The sample standard error of the mean $\left(s_{\bar{X}}\right)$ is determined using a finite population correction factor. The sample standard error is a function of the sample size and approaches zero as the sample size increases. As such, there are significant implications relating to sample size in the variability of fines for various confidence levels. In the example case, an increase in sample size will decrease the $\$ 1.50$ standard error. 
The $t$ distribution is appropriate, as compared with the standard normal distribution, because the population standard deviation is unknown. Also, the finite population correction factor is necessary. In this case, these modifications will make only a small difference, as the sample size is a relatively large one hundred and forty six.

The table below indicates the difference in the fine amounts based upon chosen probabilities (1- $\alpha$ ) that the fine does not exceed the true total population of overcharges. Clearly, as the confidence level increases, excessive fines are less likely.

Table 1: Probabilities That Fines Will Not Be Excessive and the Resulting Fine Amounts*

\begin{tabular}{|l|c|c|c|c|}
\hline Values of 1- $\boldsymbol{\alpha}$ & 0.50 & 0.80 & 0.95 & 0.99 \\
\cline { 2 - 5 } Lower Estimate of Mean & $\$ 7.84$ & $\$ 6.58$ & $\$ 5.36$ & $\$ 4.32$ \\
\cline { 2 - 5 } $\begin{array}{l}\text { Resultant Fine } \\
\text { Percentage Reduction in Fine }\end{array}$ & $\$ 62,206$ & $\$ 52,187$ & $\$ 42,557$ & $\$ 34,285$ \\
\cline { 2 - 5 }
\end{tabular}

*Standard error of $1.496, \mathrm{n}=146$

With 1 minus alpha set at 0.50 , the lower estimate of the population mean is the same as the point estimate of the population mean (the sample mean). This is the $d e$ facto value of the procedure as used by the auditor. The lower estimate of the mean is reduced as 1 minus alpha increases because the number of standard errors ( $t$ value) subtracted from the point estimate is increased. As our tolerance for error (alpha) is reduced, the resultant fine becomes smaller. The percentage reduction in fines can result in a significant decrease in the amount of the fine as a result of less tolerance for the risk of paying an excessive fine. However, the reward of using this procedure is a more justifiable and defensible audit.

\section{The Standard Error And Sample Size}

The auditor chose one hundred forty six transactions for his sample. If the sample size had been increased, the precision of the confidence interval would have been greater; resulting in a narrower dispersion of the range of possible values. This is because the sample standard error will decrease as a result of a larger sample. With this increased precision, the lower bound will approach the point estimator, resulting in a larger value being projected on to the population for determining fines. Therefore, a larger sample size will actually serve to increase the fine amount, assuming the sample mean and the sample standard deviation does not change. Therefore, increasing the sample size, in combination with the use of the lower bound, provides greater assurance that a fine is appropriate.

\section{CONCLUSIONS AND IMPLICATIONS}

The use of sampling techniques is well-established in auditing practice and serves to reduce the effort and cost in making inferences about account balances and class transactions. Statistical sampling enables an auditor to quantitatively measure and adjust for the effects of sampling risk. In a financial statement audit, the focus of the auditor is assessing whether of an account balance or class of transactions is fairly stated, so using two-tailed confidence intervals is often a reasonable approach. In a compliance audit, however, the focus may be on determining a specific amount of non-compliance, resulting in charges or fines.

Simply projecting a point estimator of the population mean to determine the amount of the fine will ensure fines or charges greater than those deserved approximately half of the time and will most likely be viewed as unnecessarily harsh by the auditee. The compliance audit example that we have provided in this paper illustrates the shortcomings of using a single-point estimator projected to a population of transactions to determine charges, fines, or penalties. Knowledge of these effects provides an auditee with significant leverage in negotiations over penalties. Successful argument of these points may significantly reduce or eliminate the penalties the auditee pays.

However, using the lower bound from a one-tailed confidence interval for projecting fines or charges will allow the auditor to specify, in advance, the risk (alpha) that a fine is larger than the actual amount of non- 
compliance. The risk of charging excessive penalties may be, in part, controlled by reducing the alpha value used in computing confidence intervals for the population mean, as derived from the sample. Essentially, the probability that an auditee will be fined more than deserved is reduced from fifty percent (using the single-point estimator) to a smaller percentage, as predetermined by establishing alpha. An auditee is more likely to perceive fair treatment in this case.

Finally, the auditor may reduce the difference between the lower bound estimate and the point estimate (the sample mean) by increasing the sample size. When sample size is increased, the standard error associated with the sample is decreased, leading to more precise estimates and (generally) larger, better substantiated fines. While larger samples mean more time and work for the auditor, the greater precision provided may well offset these costs by providing the means for the auditor to substantiate and defend the process as fair and reasonable, resulting in less frequent litigation and greater confidence in the audit by both the auditor and the auditee.

Our work here has been exploratory in nature. As a result of this research, we believe that the use of a single-point estimator derived from a sample to determine fine amounts does not provide a reasonable and defensible basis for charges or fines in a compliance audit. We have proposed a more precise way to accomplish the purpose of the audit procedure that is in keeping with generally accepted auditing standards. Use of a one-tailed confidence interval gives greater assurance that an auditee will not be fined more than is reasonable. This, in combination with larger sample sizes, improves the precision of the procedure, is more defensible, and provides the perception of a fair procedure to all parties.

\section{AUTHOR INFORMATION}

Steven W. Lamb is Chairperson and Professor of Decision Sciences in the College of Business at Indiana State University where he teaches graduate business statistics courses. He specializes in using simulation techniques to investigate statistical tools. His research has appeared in publications such as Public Personnel Management and the Journal of the Academy of Finance.

William H. Svihla is an Assistant Professor of Accounting in the College of Business at Indiana State University where he teaches courses in auditing, financial accounting, and accounting information systems. His research interests include financial contracting, financial markets, auditor decision making, and emerging professional services for CPAs.

Jeffrey S. Harper is a Professor of MIS in the College of Business at Indiana State University where he teaches graduate and undergraduate courses in Information Systems. In addition, he Dr. Harper also teaches the eCommerce Strategies course at Harvard University in the Economics and Management Program of the Harvard Summer School. Known for his research in teaching case studies, Dr. Harper's research has appeared in such publications as the Decision Sciences Journal of Innovative Education, Journal of Informatics Education and Research, Journal of the International Academy for Case Studies, Case Research Journal, and the Journal of Information Technology Management, among others. He has served as an IT consultant for such organizations as EDS, State Farm Insurance, NASA, the U.S. Justice Department, the Department of the Navy, Monroe Guaranty Insurance, and BellSouth, Inc.

\section{REFERENCES}

1. American Institute of Certified Public Accountants (AICPA) 2008. Authoritative standards for non-issuers: AU 350: Audit Sampling. New York, NY: AICPA. http://www.aicpa.org (Accessed on April 16, 2008).

2. 2001. AICPA Audit guide: audit sampling. New York, NY: AICPA.

3. $\quad$ Annulli, Thomas J., Mulrow, Jeri, and Christine Rauchle Anziano. 2000. "State Tax Audit Sampling." Corporate Business Taxation Monthly 1, no. 8: 24. Business Source Premier, EBSCO host (accessed April 30, 2008).

4. 2000. "The Wisconsin audit sampling study." Corporate Business Taxation Monthly 1 no. 8, 2428. Business Source Premier, EBSCOhost (accessed April 16, 2008). 
5. Department of Health and Human Services, Health Care Financing and Human Services. Medicare Program Integrity Manual, Chapter 3: Verifying Potential Errors and Taking Zcorrectiver Action. Rev. 248, March 28, 2008. Accessed May 15, 2008 at http://www.cms.hhs.gov/Transmittals/Downloads/R3PIM.pdf.

6. Epstein, Barry Jay. 1986. Attributes sampling: A local firm's experience. Journal of Accountancy 161, no. 1: 130-135. Business Source Premier, EBSCO/host/ (accessed April 16, 2008).

7. Federation of Tax Administrators. 2002. "Sampling for sales and use tax compliance." Task Force on EDI Audit and Legal Issues for Tax Administrators. http://www.taxadmin.org/fta/pub/sample.pdf

8. 2002. "Appendix A: Summary of state sampling practices." Updated January 2004. http://www.taxadmin.org/fta/pub/Samp2004.pdf

9. Fowler, Janet F., and James E. Foster. 1994. "Statistics, the law and government auditors' sampling procedures." Government Accountants Journal 43, no. 1: 35. Business Source Premier, EBSCOhost (accessed April 16, 2008).

10. Gavenda, Maryann. 2001. "Statistical versus nonstatistical sampling in sales \& use tax audits." 2001. Journal of State taxation Vol. 20 Issue 1, 65-73. Business Source Complete, EBSCOhost (accessed April $16,2008)$.

11. Gilbertson, David L., and Terri L. Herron. 2003. "Audit sampling methods and juror negligence awards: an expectation gap?" Journal of Applied Business Research 19, no. 1: 109.

12. Hall, Thomas W., James E. Hunton, and Bethane Jo Pierce. 2002. "Sampling practices of auditors in public accounting, industry, and government." Accounting Horizons 16, no. 2: 125-136.

13. Hitzig, Neal B. 1995. "Audit sampling: A survey of current practice." CPA Journal 65, no. 7: 54. Business Source Premier, EBSCO/host (accessed May 15, 2008).

14. Hitzig, Neal B. 2004. "Statistical Sampling Revisited." CPA Journal 74, no. 5: 30-35. Business Source Premier, EBSCO/host (accessed May 15, 2008).

15. Institute for Internal Auditors (IIA). (January 11, 2006). Practice Advisory 2100-10: Audit Sampling. http://www.theiia.org/guidance/standards-and-practices (accessed on March 22, 2008).

16. Medicare Prescription Drug, Improvement, and Modernization Act of 2003. 117 STAT. 2066. Public law 108-173. Signed December 8, 2003. Available at: http://www.ustreas.gov. Accessed: May 22, 2008

17. Messier Jr., William F., Kachelmeier, Steven J., and Kevan L. Jensen. 2001. "An Experimental Assessment of Recent Professional Developments in Nonstatistical Audit Sampling Guidance." Auditing 20, no. 1: 81. Business Source Premier, EBSCO/host (accessed May 15, 2008).

18. Mohr, Donna L. 2005. "Confidence limits for estimates of totals from stratified samples, with application to Medicare Part B overpayment audits." Journal of Applied Statistics 32, no. 7: 757-769. Business Source Complete, EBSCOhost (accessed May 4, 2008).

19. "MTC proposes model statistical sampling statute, but some fear vagueness empowers auditors. (cover story)." 2007. Sales \& Use Tax Alert 17, no. 6: 1-3. Business Source Complete, EBSCO/host/ (accessed May 22, 2008).

20. Mulrow, Jeri, Eric Falk, Tom Annulli. 2001. "Assessing state sampling audit risk." Corporate Business Taxation Monthly Vol. 3 no.1: p5-11. Business Source Complete, EBSCOhost (accessed April 16, 2008).

21. Smieliauskas, Wally. 1986. "Control of sampling risks in auditing." Contemporary Accounting Research/3, no. 1: 102-124. Business Source Premier, EBSCO/host (accessed April 16, 2008).

22. Swinamer, Kathy, Lesperance, Mary, and Hartmut Will. 2004. "Optimal Bounds Used in Dollar-Unit Sampling: A Comparison of Reliability and Efficiency." Communications in Statistics: Simulation \& Computation 33, no. 1: 109-143. Business Source Premier, EBSCO/host/ (accessed May 22, 2008).

23. Teitlebaum, A. D. and C. F. Robinson. 1975. "The Real Risks in Audit Sampling." Journal of Accounting Research 13, no. 3: 70-91. Business Source Premier, EBSCO/host (accessed May 15, 2008). 
Journal of Business \& Economics Research - January, 2009

Volume 7, Number 1

NOTES 